\title{
Tradução e adaptação de mangás: reflexões e (im)possibilidades
}

\author{
Rafael Schuabb Poll da Fonseca
}

Resumo: A tradução é uma prática cuja relevância foi ressaltada por Jakobson (1975), linguista da Escola de Praga, e Guldin (2002), estudioso de Flusser, filósofo e escritor multilíngue. Sabemos que o ato de traduzir é muito mais complexo do que um simples escambo de sinônimos entre línguas. Quando a tradução se realiza em cima de uma história em quadrinhos requer um cuidado ainda maior, já que além do texto verbal ali apresentado há outro elemento textual de igual importância: o composto imagético. Como afirma Umberto Eco (2006), a relação entre os dois compostos textuais - verbal e imagético - é bastante complexa. No caso das histórias em quadrinhos japonesas, ou mangás, essa relação é ainda mais explorada por seus autores, já que o próprio idioma japonês apresenta em sua composição um largo uso de ideogramas. Neste artigo, busco apontar as principais problemáticas da tradução de mangás para a língua portuguesa, após uma reflexão sobre a (im)possibilidade da tradução, suscitada pela leitura de textos de Jakobson e Flusser, e considerando os obstáculos apontados pelo tradutor profissional de mangás Arnaldo Oka.

Palavras-chaves: tradução, adaptação, mangá, intercâmbio cultural.

\section{Introdução}

Os mangás estavam praticamente restritos ao mercado japonês até vinte anos atrás, quando finalmente chegaram ao Ocidente a reboque do sucesso dos desenhos animados japoneses, que em sua maioria eram adaptações de mangás. Hoje, o Japão mantém o maior mercado editorial do mundo, em grande parte por conta do mercado de mangás, que também é o maior de histórias em quadrinhos. 
As particularidades dos mangás, por exemplo, os desenhos em preto e branco e as histórias geralmente finitas, são muito diferentes da maioria das histórias em quadrinhos ocidentais, como é o caso das revistas de super-heróis americanos, Disney, Turma da Mônica etc. Embora causem um estranhamento inicial no leitor acostumado com os quadrinhos do Ocidente, as particularidades dos mangás começaram a conquistar seu espaço a partir do final da década de 80 e, especificamente no Brasil, no fim do século XX, com o lançamento de Dragon Ball e Cavaleiros do Zodíaco, ambos publicados pela Editora Conrad.

Os mangás são produtos artísticos japoneses e, portanto, refletem a cultura nipônica. Dado o sucesso dos mangás nos últimos anos, eles se tornaram o principal meio de divulgação da cultura japonesa no Ocidente. Através dessas obras os leitores podem se aproximar de elementos como a moda, hábitos, gestos, humor, lições de etiqueta, moral etc. Porém, para que os leitores de mangás tenham acesso a todos esses elementos culturais da forma mais fiel possivel é preciso contar com um trabalho de tradução e adaptação muito bem executado.

A complexidade desse tipo de tradução/adaptação, a imponência do mercado japonês de histórias em quadrinhos, e sua infiltração no mercado editorial brasileiro são os grandes propulsores da minha pesquisa sobre tradução e adaptação de mangás - processos envolvidos em toda publicação de mangás no Brasil e que são, certamente, determinantes para o sucesso dessa mídia.

\section{(Im)Possibilidade da tradução}

O grande desenvolvimento dos meios de comunicação nas últimas décadas serviu como elemento catalisador para as relações entre os países e para a busca cada vez mais emergencial pela informação. Nesse contexto, em um mundo dito globalizado, os tradutores são profissionais indispensáveis, e a área dos Estudos da Tradução, segundo Maria Aparecida Salgueiro ${ }^{1}$, vem ganhando cada vez mais espaço no meio acadêmico, conquistando lugar específico dentro dos estudos da Linguística (BERNARDO, 2002:15).

A importância dos Estudos da Tradução também é validada por Roman Jakobson, um dos expoentes do Funcionalismo, ao afirmar que "a prática

1 Coordenadora do Escritório Modelo de Tradução Ana Cristina César do IL/UERJ. 
generalizada da comunicação interlingual, em particular as atividades de tradução, devem ser objeto de atenção constante da ciência linguística" (JAKOBSON, 1975:66).

$O$ linguista do Círculo Linguístico de Praga aprofunda o conceito de tradução e o eleva a um patamar muito mais abrangente do que prega 0 senso comum. Em Linguística e Comunicação, Jakobson (1975, p. 63) afirma que "o significado das palavras (...) é decididamente um fato linguístico - ou para sermos mais precisos e menos restritos - um fato semiótico." Ainda segundo ele,

o significado de um signo linguístico não é mais que sua tradução por um outro signo que lhe pode ser substituído, especialmente um signo "no qual ele se ache desenvolvido de modo mais completo", como insistentemente afirmou Peirce (JAKOBSON, 1975:64).

A partir de tais afirmações, pode-se concluir que Jakobson considera como tradução qualquer processo de interpretação de um signo. Partindo desse pressuposto, o linguista propõe a tradução como um conceito tricotômico, enumerando as três maneiras de interpretação de um signo verbal, ou seja, de traduzir um signo. São elas: a tradução intralingual, que segundo Jakobson é a "interpretação dos signos verbais por meio de outros signos da mesma língua"; a tradução interlingual, ou seja, a "interpretação dos signos verbais por meio de alguma outra língua" - que seria a tradução propriamente dita -; e a tradução inter-semiótica, que é a "interpretação dos signos verbais por meio de sistemas de signos não-verbais" (ibid.: 64-65).

É importante ressaltar que o próprio Jakobson considera que não há uma equivalência perfeita entre sinônimos de signos tanto dentro de uma única língua quanto quando duas línguas são comparadas e que, por esse motivo, diz ele, "uma palavra (...) só pode ser plenamente interpretada por meio de uma combinação equivalente de unidades de código" (ibidem: 65).

Contudo, como na tradução interlingual não se deve priorizar a simples troca de um signo por seu correspondente literal em outra língua, mas, sim, a substituição de uma mensagem por outra que lhe seja equivalente semanticamente na língua-meta $a^{2}$ a imprecisão da sinonímia não é um

2 A língua para a qual se pretende traduzir um texto, também conforme Vilém Flusser. 
fator que invalida esse tipo de interpretação de signos ${ }^{3}$, uma vez que a língua-meta sempre conseguirá moldar os recursos de que dispõe para interpretar uma nova experiência cognitiva.

Entretanto, a impossibilidade da tradução ideal, ou seja, daquela em que há a troca de uma mensagem por outra que lhe seja plenamente equivalente em outro idioma, é defendida por Vilém Flusser. Este escritor multilíngue, famoso por traduzir diversas vezes seus próprios textos para várias línguas, uma após a outra, alegando que em cada idioma o texto ganha um novo teor, afirma que a única tradução verdadeira é aquela empreendida pelo autor do texto a ser traduzido 4 (BERNARDO, 2002: 18).

Um dos maiores estudiosos de Flusser, Rainer Guldin, concorda com essa afirmação e compara o processo de tradução ao jogo conhecido como "telefone sem fio", estruturado da seguinte forma: um grupo de pessoas senta-se ao redor de uma mesa e uma delas elabora uma frase, porém, sem revelá-la aos demais. Em seguida, esse jogador sussurra essa frase para um de seus vizinhos o mais discretamente possivel, que então sussura para a pessoa seguinte e assim por diante. A brincadeira termina quando a frase, após ser sussurrada de participante para participante, chega novamente aos ouvidos do jogador que a elaborou. Nesse momento, geralmente a locução está bastante modificada em relação à sua versão original, tornando-se, por isso, risivel (Ibidem, 2002: 18-19).

Sobre tal comparação, defendendo a impossibilidade da tradução ideal, ou seja, a intraduzibilidade fundamental das línguas, Guldin afirma:

Procedimento similar, agora com um texto escrito e regras ligeiramente alteradas, também é usado na prática da tradução para refletir sobre o caráter do duplo vínculo (double-bind) de todos os processos de tradução: a (im)possibilidade de reconciliar fidelidade ao original com a necessidade de adaptá-lo ao contexto da nova língua. Essa espécie de experiência conduz em geral a uma aceitação do fracasso em processos de tradução, no que tange à adequação $e$ ao rigor. Em especial, o retorno do texto traduzido ao estágio final,

3 Além disso, Jakobson considera que essa equivalência na diferença, ou seja, a imensa variedade de articulações possivveis para expressar as mesmas ideias em diferentes idiomas, é o problema principal da linguagem e a principal preocupação da Linguística (JAKOBSON, 1975:65)

4 "(...) the only true translation is the one attempted by the author of the text to be translated", no original em inglês. 
ao momento preciso da retradução, deixa exposta a incapacidade fundamental de qualquer tradução para recuperar o sentido original (ibid.: 19).

Em oposição à valorização defendida por Jakobson da propriedade da equivalência na diferença, Guldin afirma que Flusser, durante suas múltiplas traduções, não se focava em procurar por essa unidade na diferença, mas sim utilizar como princípio criativo as diferenças que existem de uma língua para outra. Uma vez que o próprio Flusser traduzia e retraduzia seus textos, ele dominava e direcionava completamente todo o processo de tradução, evitando as perdas não intencionais que ocorrem nos textos que são traduzidos de uma língua para outra cada vez por uma pessoa diferente. Nesse caso, ocorre o que a teoria da tradução tenta evitar: borra-se a fronteira entre tradução, paráfrase e reescritura. Porém, segundo Guldin, "desde que toda forma de tradução implica um ato de interpretação", essa tarefa à qual a teoria da tradução se propõe é praticamente impossivel (Ibidem: 21).

É importante para a realização da pesquisa aqui pretendida destacar que no método de escrita e autotradução de Flusser, este não se foca no texto em si, mas nos pensamentos e motivações que levaram esse texto a ser produzido. A mecânica de seu trabalho consiste em possibilitar ao escritor distanciar-se do texto e a cada tradução acumular mais e mais pontos de vistas diferentes, gerando um texto final mais rico. Isso é viável em um texto de própria autoria, mas não em um escrito por outra pessoa. Afinal, uma vez que todo texto, em especial os artísticos, é intencionalmente estruturado de forma a comunicar ideias e informações que seu autor pretende transmitir, qualquer distúrbio que o tradutor e/ou adaptador provocar durante seu trabalho poderá trazer sérias consequências e dificultar ou mesmo impedir o bom entendimento do leitor.

No caso das histórias em quadrinhos, as traduções/adaptações mal desenvolvidas não se restringem apenas a gerar distúrbios de ordem linguística e cultural. Nessa mídia, em que os desenhos e os textos constituem, segundo Umberto Eco, uma "linguagem muito articulada e de absoluta precisão" (ECO, 2006: 131), observa-se também a influência negativa que esse tipo de problema pode gerar no componente artístico de uma obra. No caso dos mangás, que comportam uma maior quantidade de texto sobreposicionado por causa da ampla utilização de onomatopeias (cujas diversas tipografias possuem suas próprias significações), e cujos textos 
originalmente são escritos em sentido vertical (o que faz com que os autores de mangás elaborem balões de texto também verticalizados), as interferências artísticas que a tradução/adaptação pode gerar são enormes e perceptíveis por qualquer leitor. Na grande maioria das edições brasileiras de mangás podemos encontrar, por exemplo, diversos balões que se tornam grandes demais para o texto em português e, portanto, escrito horizontalmente.

\section{Obstáculos presentes na tradução e adaptação de mangás}

Em palestra realizada no ano de 2008 no XIX Encontro Nacional de Professores Universitários de Língua, Literatura e Cultura Japonesa, Arnaldo Massato Oka, tradutor de diversos mangás publicados no Brasil pela editora JBC, comentou sobre seis aspectos que estão presentes nos mangás e se apresentam como problemas durante o processo de tradução e adaptação de mangás. São eles: sentido de leitura, citações, transliteração e adaptação de nomes próprios, ditados e trocadilhos, gramática e onomatopeias. $^{5}$

Além dos seis aspectos reconhecidos como problemáticos por Oka, acrescentei a tradução de tradução, totalizando assim sete obstáculos que devem ser superados pelos tradutores de mangás. Esses obstáculos servirão de base para toda a comparação argumentativa exposta neste trabalho em relação à tradução e adaptação oficiais adotadas no Brasil.

\section{Sentido de leitura}

O sentido de leitura de uma publicação é um obstáculo sem solução, pois deriva da escrita e da cultura do seu país de origem. No caso dos mangás, a ordem é, obviamente, a adotada no Japão, ou seja, a leitura é feita da direita para a esquerda, sendo, assim, oposta à ordem comumente utilizada no Brasil, o que a leva a ser encarada como um elemento que afasta possíveis novos leitores. Por outro lado, para os consumidores mais aficionados, a manutenção do sentido de leitura original da obra é símbolo de qualidade na publicação de um mangá.

5 Oka designa os aspectos listados como problemas (OKA, p. 178), mas optei por chamálos de "obstáculos", uma vez que esta palavra transmite melhor a ideia de desafio a ser superado do que "problema", que carrega um aspecto significativo mais negativo. 
As primeiras editoras que trouxeram os quadrinhos japoneses para - Brasil, provavelmente por acreditarem que a ordem de leitura japonesa poderia ser um empecilho para suas vendagens, publicaram-nos com a ordem de leitura típica ocidental. Foram os casos de Lobo Solitário (editora Cedibra, em 1988, e Sampa, em 1990), Akira (Globo, em 1990) e Crying Freeman (Sampa, em 1992), entre outras obras. Entretanto, mesmo com a decisão editorial de utilizar a ordem de leitura brasileira, esses mangás não conseguiram popularizar o gênero no país.

A opção pelo sentido de leitura oriental se explica por três motivos fundamentais:

- maior aproximação com a edição original japonesa;

- não inversão de onomatopeias (assunto que será desenvolvido adiante);

- não adulteração do universo criativo da história, uma vez que a publicação de um mangá em ordem de leitura ocidental resulta na total inversão dos desenhos, tranformando, por exemplo, pessoas destras em canhotas e vice-versa.

\section{Citações}

Antes de desenvolvermos a análise sobre citações, é necessário esclarecer que considero aqui como citação qualquer nome, frase ou assunto que faz referência a pessoas famosas, filmes, músicas, livros, histórias em quadrinhos, etc., sejam estas referências direcionadas a elementos do próprio Japão ou do exterior.

São dois os obstáculos provocados pelas citações: primeiro é preciso que o tradutor/adaptador seja antenado com cultura pop japonesa $e$ internacional e tenha vasto conhecimento sobre o universo nipônico em geral; o segundo é o fato de que o quadrinista japonês se preocupa que seu mangá seja de fácil leitura especificamente para os japoneses. Dessa forma, assim como podem ocorrer citações compreensíveis a todos os leitores (japoneses e estrangeiros) - como, por exemplo, uma citação à cantora Madonna ou ao célebre Leonardo da Vinci -, podem ocorrer também algumas muito intrínsecas à cultura japonesa, portanto distantes do entendimento de uma parte dos leitores do Brasil.

Cabe ao tradutor/adaptador considerar que citações necessitam ser esclarecidas para os consumidores brasileiros. Na edição brasileira do mangá Naruto, por exemplo, há todo um cuidado para informar o leitor 
sobre palavras e elementos culturais japoneses citados na história, na tentativa de evitar que o leitor fique perdido em alguns momentos. A editora Panini optou por colocar um "Glossário" no fim de cada volume, elucidando alguns termos, em lugar de elucidá-los na própria página em que aparecem. A decisão é justificável, uma vez que alguns esclarecimentos são necessariamente longos e o espaço entre os quadrinhos de uma página são, em geral, pequenos. Os termos explicados no glossário abrangem áreas as mais variadas possíveis: geografia, culinária, videogames, medicina, sistema de educação japonesa etc.

A questão das citações também está presente nas partes de free talking ${ }^{6}$ dos mangás. Como já foi dito neste trabalho, cada vez mais as editoras brasileiras de quadrinhos japoneses têm se comprometido com a fidelidade ao produto original e, assim, é comum que as partes de free talking sejam traduzidas e mantidas nas edições nacionais. A questão é que, nesses espaços, o autor tem liberdade para falar sobre assuntos em geral e isso acarreta um grande número de citações: lugares que o quadrinista visitou, jogos de videogames, artistas, outros mangás, etc. Algumas dessas citações são explicadas pelo próprio autor, mas outras não, provavelmente por ele considerar como informações de conhecimento dos leitores japoneses.

\section{Transliteração e adaptação de nomes próprios e termos japoneses}

Nomes próprios precisam ser escritos em letras romanas, e termos japoneses que não podem ser traduzidos precisam ser adaptados ou transliterados e, neste segundo caso, explicados como as citações (tratadas no capítulo anterior).

Em relação aos nomes próprios, as fontes de maior complicação para os tradutores/adaptadores são o prolongamento e as diferenças entre os caracteres que constam no alfabeto do português, mas não constam no silabário do japonês, como é o caso da letra "L".

No caso do prolongamento, por exemplo, existe a prática, da qual eu discordo bastante, de se colocar um " $H$ " depois de uma vogal para prolongá-

6 Muito comuns nos quadrinhos japoneses, o free talking é um espaço no qual o autor tem a possibilidade de conversar com os leitores de sua obra. Muitas vezes, o assunto gira em torno das dificuldades de se desenhar uma série de mangás - tempo curto, um ou outro incidente, etc. - ou de hobbies do quadrinista. 
la, principalmente quando em nomes próprios. É o caso do nome de um personagem do mangá Cavaleiros do Zodíaco (publicado pela Conrad), cujo nome foi romanizado como "Dohko", enquanto em japonês é "ドウコ" ("Douko").

Os leitores brasileiros não têm obrigação de conhecer as regras do idioma japonês, e eu acredito que escrever "Douko" não sinalizaria corretamente a sonoridade do nome (embora me pareça mais natural que "Dohko"). A meu ver, portanto, o ideal seria romanizar esse nome como "Dôko", com o traço mácron ${ }^{7}$ em cima da vogal prolongada. A romanização para prolongamentos nas demais palavras seguiria o mesmo método: "sensei" seria escrito "sensç" e "otousan" seria "otôsan".

Sobre a questão entre o " $L$ " e o " $R$ " do idioma japonês, acredito que é preciso chegar a um consenso sobre qual dos dois utilizar em nomes e termos genuinamente japoneses - nesse caso, a opção por " $R$ " seria mais bem-vinda, uma vez que é a representação mais tradicional da coluna do "ら" ("ra"), do alfabeto japonês.

Por outro lado, é importante que haja uma investigação sobre a origem dos nomes que serão transliterados. Novamente citando o mangá Cavaleiros do Zodíaco, há um personagem francês cujo nome é inspirado no escritor Albert Camus. Em japonês, seu nome é escrito "カミュ" ("Kamyu"), que é a interpretação do silabário japonês para a pronúncia francesa do nome "Camus". Na edição brasileira, porém, o nome do personagem era escrito "Kamus", ou seja, não era nem a versão escrita em japonês, nem a versão de origem.

\section{Ditados, expressões idiomáticas e trocadilhos}

Alguns dos elementos mais complexos na adaptação de mangás são os ditados, as expressões idiomáticas e os trocadilhos. Essa dificuldade de tradução/adaptação se deve à relação muito íntima entre esses elementos e a cultura e língua japonesas. Muitas vezes é impossível encontrar um correspondente exato para traduzir essas expressões, por isso acredito que, dependendo do público a que se destina, pode ser mais válido apresentar uma tradução literal e explicar o jogo de ideias e/ou palavras que está presente. Vejamos.

\footnotetext{
O mácron é um sinal em forma de traço horizontal utilizado em algumas línguas, como o
} próprio latim, para indicar que a vogal por ele assinalada é longa. 
A expressão idiomática "neko no hitai", por exemplo, funciona como um adjetivo em língua japonesa; em português seria algo como "muito curto(a)". Entretanto, se traduzido literalmente, teríamos a expressão substantivada "testa de gato", que aos brasileiros nem de longe remete ao significado entendido pelos japoneses. $O$ tradutor poderia, então, simplesmente converter tal expressão a "muito curto(a)", ou algo similar, ou manter a tradução literal "testa de gato" e acrescentar uma nota de rodapé com a explicação.

Tendo em vista que há diferentes gêneros de mangás, destinados a públicos variados, de crianças a adultos, me parece que, na falta de uma expressão idiomática em português com sentido correspondente ao da expressão em japonês, seria interessante: 1) no caso de público infantil, traduzir mantendo o sentido - no presente exemplo, "muito curto(a)" -, evitando um maior número de notas de rodapé e facilitando a leitura; e 2) no caso de público jovem e adulto, traduzir literalmente e acrescentar uma nota de rodapé, o que é culturalmente mais enriquecedor e também mais ao agrado desses leitores, dada sua constante cobrança pela máxima fidelidade possível entre os mangás publicados no Brasil e seus originais japoneses.

\section{Gramática}

O obstáculo gramatical se configura pela estrutura frasal diferenciada do japonês em relação ao português, em especial no que diz respeito à posição do verbo e do objeto. Essa característica gera dificuldade aos tradutores/adaptadores principalmente quando há uma frase extensa e dividida entre diferentes quadrinhos.

Além disso, a diferença na posição entre verbo e objeto torna complexa a manutenção da carga dramática e do suspense em certos momentos na edição em português. Um exemplo clássico é a frase "Anata wo aishiteru", que pode ser traduzida como "eu te amo", em português. Para ficar mais claro, imaginemos um mangá em japonês em que certa página termine com dois personagens se encarando e um deles dizendo "Anata wo..." - que pode ser traduzido por "você", mas na função de objeto. $O$ leitor fica na expectativa de saber o que acontecerá na página seguinte, como a frase se concluirá.

Porém, se um tradutor/adaptador apenas traduzir a frase para o português seguindo a ordem frasal natural da língua portuguesa, essa mesma 
página terminará com "(Eu) amo...", destruindo todo o suspense que o quadrinista quis criar para a cena. Afinal, com dois personagens se encarando e um deles dizendo "Eu amo..." não é difícil imaginar como terminará a frase na próxima página.

Nesse caso, seria melhor traduzir de uma forma que o verbo (que neste caso é o grande elemento a ser revelado) fique na página seguinte. Uma boa opção é manter na primeira página "Eu..." e na posterior "te amo", pois tanto o sentido quanto o suspense são mantidos tais quais na versão original.

\section{Onomatopeias}

A tradução de onomatopeias no processo de adaptação do japonês para o português é muito mais complexa do que ocorre com a maioria das obras cuja língua original é outra. É tradicionalmente ampla a utilização de onomatopeias na fala e na escrita do japonês, enquanto na língua portuguesa essa utilização é bem mais reduzida. Em decorrência disso, os tradutores são muitas vezes obrigados a inventar onomatopeias que não são dicionarizadas em português.

Em português, chama-se onomatopeia a atribuição da capacidade que certos sons linguísticos ou seu agrupamento têm para imitar ou sugerir determinados ruídos (LIMA, p. 479). Desse modo, o uso de onomatopeias nessa língua ocorre com a função de indicar certo som. Podemos citar, como exemplo, "miau" para sugerir miado de gato.

No caso da língua japonesa, porém, além das onomatopeias que funcionam como sinalizadores de sons, há também aquelas que são utilizadas para a sugestão de certa situação, chamadas, em japonês, de gitaigo e gijougo e, em português, de mímesis (LEITÃO, p. 375). Há no japonês, por exemplo, "ごごごご " ou "ゴゴゴゴ", lê-se "gogogogo", que indica uma atmosfera ameaçadora, e até mesmo uma onomatopeia para expressar ausência de sons no ambiente da cena: "しーん" ou "シーン", lê-se "shîn", (Nihongo Resources, http://www.nihongoresources.com/sfxbrowse, acessado em 15/6/2010).

Para falantes de um idioma como o português, no qual as onomatopeias são utilizadas exclusivamente para indicar sonoridade $e$, desse modo, assemelham-se a um registro gráfico do som que representam, pode ser complexo o entendimento do uso das gitaigo e gijougo japonesas. Entretanto, é importante ressaltar que essa concepção de onomatopeias en- 
quanto vocábulos motivados (ou seja, mera representação gráfica do som que se ouve) não é um consenso entre os estudiosos de línguas. Para a corrente linguística do Estruturalismo, por exemplo, segundo Saussure:

Quanto às onomatopéias autênticas (aquelas do tipo glu-glu, tiquetaque, etc.), não apenas são pouco numerosas, mas sua escolha é, em certa medida, arbitrária, pois que não passam de imitação aproximativa e já meio convencional de certos ruídos. Além disso, uma vez introduzidas na língua, acabam envolvidas na mesma evolução fonética, morfológica, etc., que sofrem as outras palavras: prova evidente de que se perdeu parte de seu caráter primitivo para adquirir o de signo linguístico comum, que não é motivado. (SAUSSURE, p. 94-95)

A partir do fragmento acima, torna-se perceptível que a compreensão de onomatopeia enquanto simples registro gráfico de uma sonoridade é um conceito muito limitado. Quando consideramos as gitaigo e gijougo japonesas, isso se torna ainda mais evidente.

\section{Retradução}

A tradução direta já é, em si, uma versão de um texto em outro idioma. Quando a tradução é feita tendo como base outra tradução e não o próprio original, os problemas gerados durante o processo tendem a se multiplicar: se torna a versão de uma versão do original.

Assim como se deu com os primeiros mangás que foram publicados no Brasil (no fim dos anos 80 e começo dos 90), hoje ainda há quadrinhos japoneses que chegam aqui usando como referência edições que não são japonesas, mas traduções das edições japonesas.

A edição brasileira de Cavaleiros do Zodíaco tem como ponto de partida a edição francesa. Isso explica, por exemplo, porque a onomatopeia "シーン" ficou com a tradução "silence", que é "silêncio" em francês, na publicação brasileira. A revisão do mangá não percebeu o deslize nem mesmo quando fizeram uma segunda edição, "corrigindo" os problemas de tradução e de adaptação da primeira versão: o erro foi mantido.

Outro exemplo de dificuldade gerada pela "tradução de tradução" aliada à problemática da adaptação de nome próprio: Na França, o personagem "ルネ" (lê-se "rune"), ficou conhecido como "Renê". A tradução brasileira adotou "Lune", uma das possibilidades - já que a ausência do "L" 
de início de sílaba no japonês possibilita a leitura de "ル " tanto como "ru" quanto como "lu" -, mas cometeu o deslize de manter "Renê" num quadrinho seguinte (esse engano, entretanto, foi corrigido na segunda edição brasileira do mangá).

Outro problema é o fato de que a versão com que se tem que trabaIhar pode já conter edições e censuras na imagem e/ou no texto. No caso de Naruto, os arquivos com que a editora Panini trabalha vêm dos Estados Unidos e contêm esses dois tipos de problemas, que desagradam muito aos fãs.

\section{Conclusão}

A enorme diferença cultural entre o Japão e o Brasil é incontestável e é justamente sobre o profundo abismo cultural que separa o Ocidente do Oriente que o tradutor/adaptador de histórias em quadrinhos japonesas precisa se deslocar, de um lado para outro, em sua prática profissional.

A diferença cultural somada à complexidade da relação entre imagem e verbo presente nas histórias em quadrinhos, especialmente nos mangás (pelos motivos já citados no presente artigo), apresenta aos tradutores um grande desafio operacional.

Entretanto, assim como afirma Jakobson, é possível, sim, realizar a tradução desses expoentes artísticos japoneses, ainda que muitas vezes seja necessário dar voltas em torno de uma pequena expressão para que seu sentido se torne o mais aproximado possível do original, em lugar de partir direto para uma busca por sinônimos.

Através de um estudo mais direcionado aos obstáculos aqui apresentados, ao tradutor cabe buscar soluções viáveis, pensando pelo viés da tradução/ adaptação, mas sem, entretanto, ir contra as pendências editoriais relacionadas - já que o ideal, no caso, é produzir um material que, na prática, atenda a uma relação de custo (da editora)/ benefício (dos leitores).

\section{Referências}

BARTHES, Roland. Elementos de semiologia. 13. ed. São Paulo: Cultrix, 2006. 
BERNARDO, Gustavo. As margens da tradução. Rio de Janeiro: Caetés, 2002.

ECO, Umberto. Apocalípticos e integrados. 6. ed. São Paulo: Perspectiva, 2006.

JAKOBSON, Roman. Linguística e comunicação. 10. ed. São Paulo: Cultrix, 1975.

LEITÃO, Renata Garcia de Carvalho. "As onomatopéias japonesas e suas traduções/adequações nos mangás traduzidos para o português". In: Anais do XIX encontro nacional de professores universitários de língua, literatura e cultura japonesa. Rio de Janeiro: Gráfica UFRJ, 2008.

LIMA, Rocha. Gramática normativa da língua portuguesa. 39. ed. Rio de Janeiro: José Olympio, 2000.

LUYTEN, Sonia M. Bibe. "Onomatopeias e mímesis no mangá: a estética do som". In: Revista USP, nr. 52, São Paulo CCS-USP, dez/jan/fev 20012002, p. 176-188.

2000.

Mangá: o poder dos quadrinhos japoneses. 2 ed. São Paulo: Hedra,

MOLINÉ, Alfons. O grande livro dos mangás. São Paulo: JBC, 2004.

NAGADO, Alexandre. Almanaque da cultura pop japonesa. São Paulo: Via Lettera, 2007.

NETO, Guilherme. Mangás: uma leitura de jovens cariocas e paulistas. Rio de Janeiro: 2009.

OKA, Arnaldo Massato. "Tradução e adaptação de mangás para o português". In: Anais do XIX encontro nacional de professores universitários de língua, literatura e cultura japonesa. Rio de Janeiro: Gráfica UFRJ, 2008.

SATO, Cristiane Akune. Japop - o poder da Cultura Pop Japonesa. São Paulo: NSP Hakkosha, 2007.

SAUSSURE, Ferdinand de. Curso de linguística geral. São Paulo: Cultrix, 1969.

\section{Websites}

Eo Brasil conheceu os mangás...

Disponivel em: http://www.conexaoaluno.rj.gov.br/especiais-17b.asp (acessado em 7 mai. 2010). 


\section{Mangá.}

Disponivel em http://www.japaoonline.com.br/pt/manga2.htm (acessado em 7 mai. 2010).

Nihongo Resources.

Disponivel em http://www.nihongoresources.com/dictionaries/ onomatopoeia.html (acessado em 15 jun. 2010).

Os estilos de escrita japonesa.

Disponivel em http://www.linguajaponesa.com.br/estilos-de-escritajaponesa.html (acessado em 20 mai. 2010). 